\title{
OS ESPAÇOS PÚBLICOS DE LAZER NA CIDADE DE MANHUAÇU - MG: O CASO DO ESTÁDIO JUCELINO KUBITSCHEK
}

\section{Larissa Ferreira Evangelista ${ }^{1}$ Fernanda Cota Trindade ${ }^{2}$}

Resumo: Os espaços púbicos de lazer são elementos fundamentais na construção social e física urbana da cidade como um todo, pois melhoram a qualidade de vida da população quando são capazes de promover interações sociais. O objetivo do presente artigo é reafirmar que as cidades necessitam de espaços públicos para recreação dos indivíduos, tornando-a um local voltado para a população. Em Manhuaçu/MG, as áreas públicas de lazer são pouco valorizadas e utilizadas pela população, o que leva à sua degradação. O Estádio Juscelino Kubitschek apresenta localização privilegiada na malha urbana e atividades pré-existentes que indicam a possibilidade de melhorar seu uso. A inserção de um parque urbano no local contribui para potencializar as relações sociais entre os indivíduos e fomentar o desejo de uma cidade sustentável inserindo verde na malha urbana

Palavras-chave: Parque Urbano; Socialização; Integração; Paisagem urbana.

\footnotetext{
1 Graduanda em Arquitetura e Urbanismo pela Faculdade de Ciências Gerenciais da cidade de Manhuaçu/MG, Brasil. E-mail: agenciafranzonni@homail.com.

2 Mestre em Arquitetura e Urbanismo pela Universidade Federal do Espírito Santo - UFES/ Manhuaçu/MG, Brasil. E-mail: fercotat@hotmail.com.
} 